\title{
An application of earthquake prediction algorithm M8 in eastern Anatolia at the approach of the 2011 Van earthquake
}

\author{
Masoud Mojarab ${ }^{1}$, Vladimir $\operatorname{Kossobokov}^{2,3}, \operatorname{Hossein~Memarian~}^{1, *}$ and Mehdi Zare ${ }^{4}$ \\ ${ }^{1}$ School of Mining Engineering, University of Tehran, Tehran, Iran. \\ ${ }^{2}$ Institute of Earthquake Prediction Theory and Mathematical Geophysics, Russian Academy of Sciences, \\ Moscow, Russian Federation. \\ ${ }^{3}$ Institut de Physique du Globe de Paris, Paris, France. \\ ${ }^{4}$ Seismology Research Center, International Institute of Earthquake Engineering and Seismology (IIEES), \\ Tehran, Iran. \\ ${ }^{*}$ Corresponding author.e-mail: memarian@ut.ac.ir
}

On 23rd October 2011, an M7.3 earthquake near the Turkish city of Van, killed more than 600 people, injured over 4000, and left about 60,000 homeless. It demolished hundreds of buildings and caused great damages to thousand others in Van, Ercis, Muradiye, and Çaldıran. The earthquake's epicenter is located about $70 \mathrm{~km}$ from a preceding M7.3 earthquake that occurred in November 1976 and destroyed several villages near the Turkey-Iran border and killed thousands of people. This study, by means of retrospective application of the M8 algorithm, checks to see if the 2011 Van earthquake could have been predicted. The algorithm is based on pattern recognition of Times of Increased Probability (TIP) of a target earthquake from the transient seismic sequence at lower magnitude ranges in a Circle of Investigation (CI). Specifically, we applied a modified M8 algorithm adjusted to a rather low level of earthquake detection in the region following three different approaches to determine seismic transients. In the first approach, CI centers are distributed on intersections of morphostructural lineaments recognized as prone to magnitude $7+$ earthquakes. In the second approach, centers of CIs are distributed on local extremes of the seismic density distribution, and in the third approach, CI centers were distributed uniformly on the nodes of a $1^{\circ} \times 1^{\circ}$ grid. According to the results of the M8 algorithm application, the 2011 Van earthquake could have been predicted in any of the three approaches. We noted that it is possible to consider the intersection of TIPs instead of their union to improve the certainty of the prediction results. Our study confirms the applicability of a modified version of the M8 algorithm for predicting earthquakes at the Iranian-Turkish plateau, as well as for mitigation of damages in seismic events in which pattern recognition algorithms may play an important role.

\section{Introduction}

In the area under study (figure 1), the 23 October 2011, M7.3 Van earthquake had more than 600 victims and caused massive damages in several cities, including Van, Ercis, Muradiye and Caldıran (Zare et al. 2011). The hypocenter was located near the Tabanli village at a depth of $16 \mathrm{~km}$ (USGS 2011) (figure 2). The earthquake resulted from the movement along the $28 \mathrm{~km}$ segment of the Van fault

Keywords. Earthquake prediction; pattern recognition; M8 algorithm; time of increased probability (TIP); circle of investigation (CI); Van earthquake. 


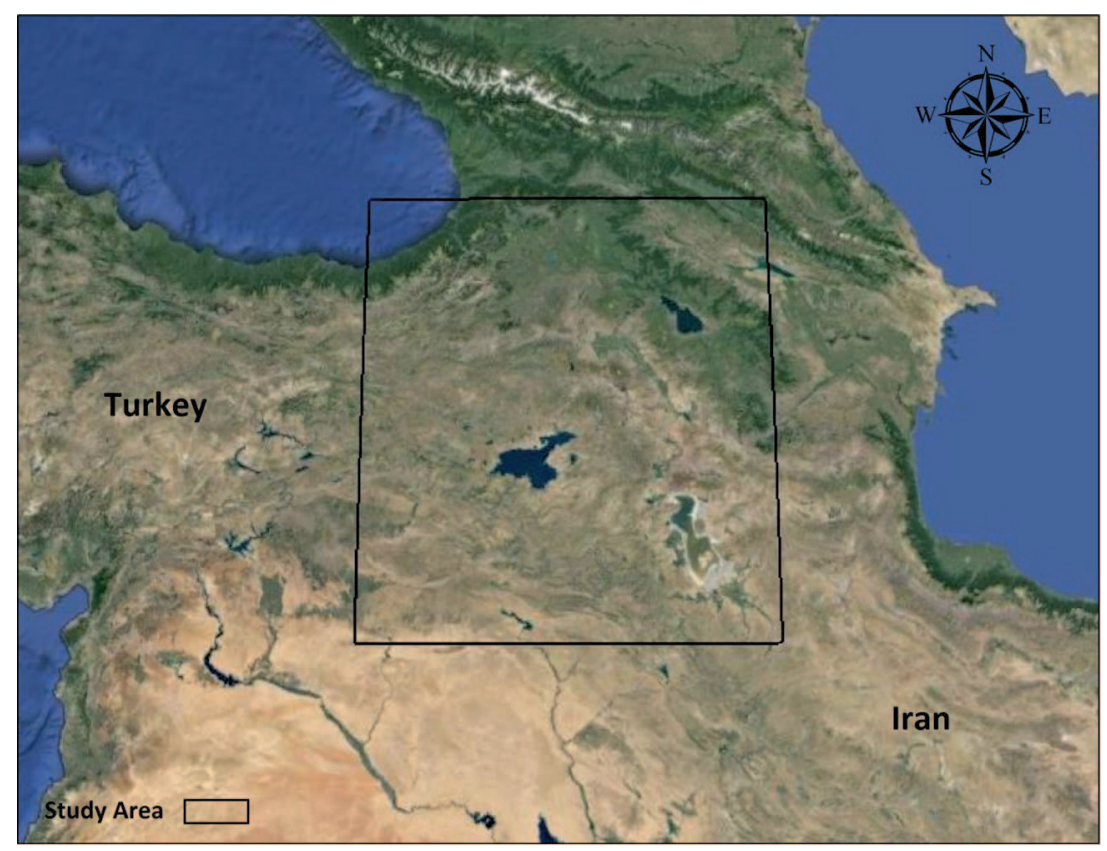

Figure 1. The area under study. The study area is located on Google map with a black border.

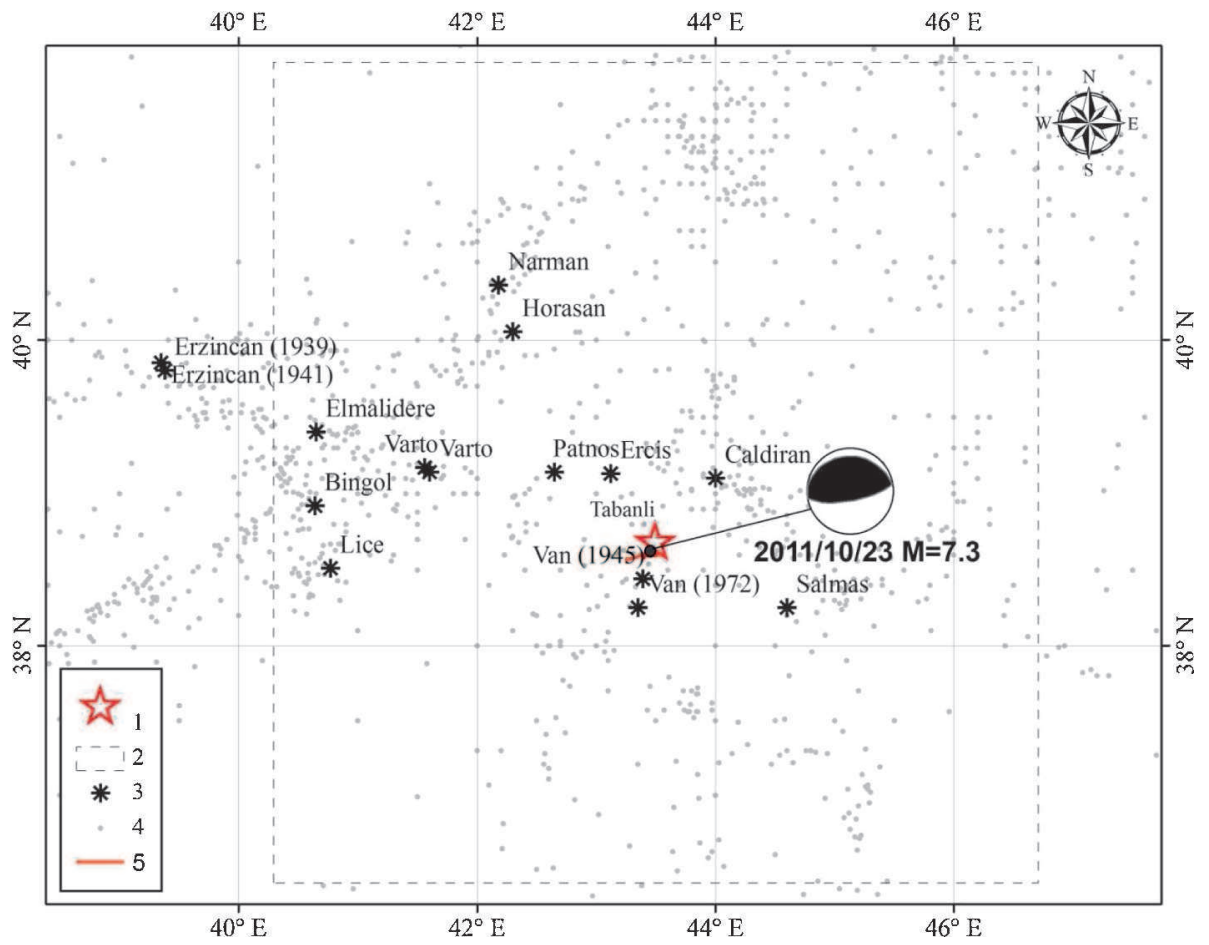

Figure 2. Seismic settings in the study area. (1) Epicenter of the 23 November 2011 Van earthquake; (2) area under study; (3) historical earthquakes which are distributed in the area under study; (4) epicenter of earthquakes reported by the USGS/NEIC Global Hypocenters' Data Base (GHDB) system in the period of 1900-2010; (5) Van fault with $28 \mathrm{~km}$ length.

with the north aspect slope and was felt not only in eastern Turkey, but also as far as northwestern Iran (Emre et al. 2011).

The seismic history of the eastern Anatolian region before the 2011 Van earthquake is summed up in table 1 (Ambraseys 1988, 2009). The 24 November 1976, M7.3 Çaldıran-Muradiye earthquake occurred $20 \mathrm{~km}$ northeast of Muradiye, in the Van province of eastern Turkey, just about $70 \mathrm{~km}$ far from the epicenter of the 2011 Van earthquake. The earthquake also had a maximum intensity $\mathrm{X}$ on the Modified Mercalli Intensity (MMI) scale. The area of severe damage, where over $80 \%$ of the buildings were destroyed, covered $2000 \mathrm{~km}^{2}$. 
There were about 5000 victims (Gulkan et al. 1978). The 6 May 1930, M7.2 Salmas earthquake occurred further to the east from the 2011 epicenter. The earthquake measured 7.2 on the Richter scale and 7.4 surface wave magnitude and resulted in 2500 direct fatalities. One foreshock occurred prior to the rupture, and multiple aftershocks followed the main event (Tchalenko and Berberian 1974).

Thus, it is evident that eastern Anatolian zone shows potential of an earthquake with magnitude 7 and more. It raises a question whether the time of such earthquakes in the region are predictable by application of reliable algorithms? United States National Research Council, Panel on Earthquake Prediction of the Committee on Seismology recommended the following definition of earthquake prediction (Allen et al. 1976):

"An earthquake prediction must specify the expected magnitude range, the geographical area within which it will occur, and the time interval within which it will happen with sufficient precision so that the ultimate success or failure of the prediction can readily be judged. Only by careful recording and analysis of failures as well as successes can the eventual success of the total effort be evaluated and future directions charted. Moreover, scientists should also assign a confidence level to each prediction."

Table 1. Historical earthquakes in eastern Anatolian region (Ambraseys 1988, 2009).

\begin{tabular}{rrrrrrrll}
\hline No. & Year & Month & Day & Lat. & Long. & Ms & Io & Earthquake name \\
\hline 1 & 1983 & Oct & 30 & 40.35 & 42.18 & 6.7 & VIII & Narman \\
2 & 1976 & Nov & 24 & 39.1 & 44 & 7.1 & IX & Caldiran \\
3 & 1975 & Sep & 6 & 38.51 & 40.77 & 6.6 & IX & Lice \\
4 & 1972 & Jun & 16 & 38.25 & 43.35 & 4.9 & VIII & Van \\
5 & 1971 & May & 22 & 38.92 & 40.64 & 6.8 & IX & Bingől \\
6 & 1966 & Aug & 19 & 39.17 & 41.56 & 6.8 & IX & Varto \\
7 & 1959 & Oct & 25 & 39.14 & 41.6 & 4.9 & VIII & Varto \\
8 & 1949 & Aug & 17 & 39.4 & 40.65 & 6.9 & IX & Elmalidere \\
9 & 1945 & Nov & 20 & 38.44 & 43.39 & 4.8 & VII & Van \\
10 & 1941 & Sep & 10 & 39.13 & 43.12 & 5.9 & VIII & Ercis \\
11 & 1941 & Nov & 12 & 39.85 & 39.35 & 5.9 & VIII & Erzincan \\
12 & 1939 & Des & 26 & 39.8 & 39.38 & 7.8 & XI & Erzincan \\
13 & 1930 & May & 6 & 38.25 & 44.6 & 7.2 & X & Salmas \\
14 & 1924 & Sep & 13 & 40.05 & 42.3 & 6.8 & IX & Horasan \\
15 & 1903 & Apr & 28 & 39.14 & 42.65 & 7 & X & Patnos \\
\hline
\end{tabular}

Table 2. Classification of earthquake prediction accuracy. Approximate temporal time of earthquake occurrence being related to the rupture size $L$ of the incipient earthquake.

\begin{tabular}{llll}
\hline \multicolumn{2}{c}{ Temporal, in years } & \multicolumn{1}{c}{ Spatial, in source zone size (L) } \\
\hline Long-term & 10 & Long range & Up to 100 \\
Intermediate-term & 1 & Middle range & $5-10$ \\
Short-term & $0.01-0.1$ & Narrow range & $2-3$ \\
Immediate & 0.001 & Exact & 1 \\
\hline
\end{tabular}

Table 3. Effectiveness of the algorithm M8 (after Kossobokov 2013).

\begin{tabular}{|c|c|c|c|c|}
\hline \multirow[b]{2}{*}{ Test period } & \multicolumn{2}{|c|}{ Target earthquakes } & \multirow{2}{*}{$\begin{array}{c}\text { Alarm volume } p \\
(\%)\end{array}$} & \multirow{2}{*}{$\begin{array}{c}\text { Confidence } \\
\text { level }(\%)\end{array}$} \\
\hline & Predicted & Total & & \\
\hline \multicolumn{5}{|c|}{ Prediction of earthquakes with magnitude M8.0+ } \\
\hline 1985-2012 & 16 & 21 & 32.84 & 99.99 \\
\hline 1992-2012 & 14 & 19 & 29.80 & 99.99 \\
\hline \multicolumn{5}{|c|}{ Prediction of earthquakes with magnitude M7.5+ } \\
\hline $1985-2012$ & 40 & 68 & 28.73 & 99.99 \\
\hline $1992-2012$ & 30 & 56 & 23.14 & 99.99 \\
\hline
\end{tabular}


The earthquake prediction algorithms, based on pattern recognition methods, offer an answer to the question stated above, by indicating the times of increased probability, TIPs, in a specified range of time, location, and magnitude. One of the important time and location classifications is illustrated in table 2. It should be noted that not only the 'short-term exact' class, but a wide variety of other possible combinations might be useful for mitigation of seismic risks. Moreover, having in mind the complexities of the Earth lithosphere, in particular, its blocks-and-faults structure and their evidently non-linear dynamics, the 'short-term exact' prediction accuracy might be unreachable, in principle (Hough 2009).

According to table 2, the times of increased probability (TIPs) diagnosed by the M8 algorithm (briefly described in appendix A), whose original version was published in 1987 (Keilis-Borok and Kossobokov 1987) and is presently available in the IASPEI software library (Kossobokov 1997), belong to the class of intermediate-term middlerange predictions. The algorithm has passed a rigid testing in the ongoing global experiment started in 1992 (Healy et al. 1992). The confidence level achieved in more than 20 years of the ongoing global testing (table 3), along with the results of retrospective studies targeting magnitude ranges other than M8.0+ and M7.5+ (KeilisBorok and Kossobokov 1990; Kossobokov 2013), encourages the M8 algorithm real-time applications on a regional scale. In this study, we attempt to justify such an application in the region of the Turkish-Iranian plateau.

\section{Anatolian and Persia-Tibet plateau}

Recognition of discrete plate tectonics between Africa and Eurasia was reported by McKenzie (1972). He combined seismicity, geology and topographic data and proposed that Anatolian plate is escaping towards west due to Arabia-Eurasia collision. Recent GPS investigations proved McKenzie's model (Bird 2003). More recently, a global study tried to identify tectonic boundaries for the entire world; for which most of information was collected from literatures (Bird 2003) (figure 3). A global study shows that continental lithosphere in Middle East is divided into Anatolian, Arabian, Eurasia, and Persia-Tibet discrete plates, while many others emphasized independency of Anatolian plate (McKenzie 1972; Bird 2003; McClusky et al. 2000; Reilinger et al. 2006). In the present study, the area of investigation of seismic activity in advance the 2011 Van earthquake has been selected between Anatolian, Arabia, and Tibet plates, which mostly cover the Persia plate. Persia and Tibet are the two main plateaus of the Alpine-Himalayan collision system (Sengör and Kidd 1979; Dewey

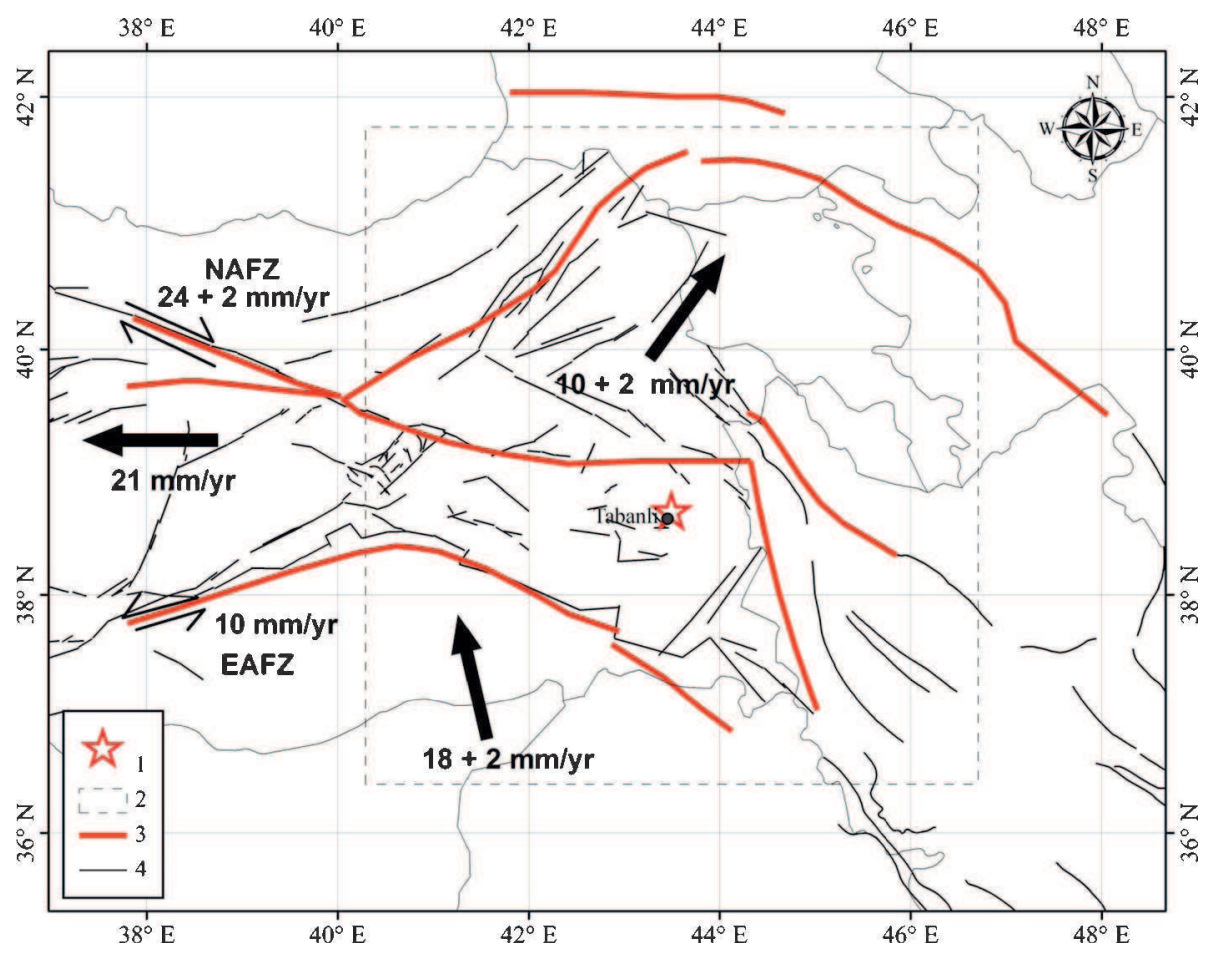

Figure 3. Tectonic settings in the study area. (1) Epicenter of the 23 November 2011 Van earthquake; (2) area under study; (3) I-rank lineaments (after Gelfand et al. 1974a); (4) active faults. NAFZ: North Anatolian fault zone. EAFZ: East Anatolian fault zone. 
et al. 1986). The Persia plateau extends from eastern Anatolia to eastern Iran, and typically has elevations of $1.5-2 \mathrm{~km}$, decreasing to about $500 \mathrm{~m}$ in eastern Iran. The basement of Persia plateau consists of micro-plates interspersed with zones of ophiolites and melanges accreted to each other, formed on this part of Eurasia by the late Cretaceous or early Tertiary (Sengör 1990; Berberian et al. 1982). Westward transport of the Anatolian plate occurs by slip on the East and North Anatolian faults (McKenzie 1972).

The left-lateral East Anatolian fault accommodates motion between the Arabian and Anatolian plates. Historical slip rates, based on seismic moments of earthquakes along the East Anatolian fault, are $6-10 \mathrm{~mm} \mathrm{yr}^{-1}$ (Taymaz et al. 1991). The GPS-derived slip rate is $9 \pm 1 \mathrm{~mm} \mathrm{yr}^{-1}$ and slip rate for the North Anatolian fault is $24 \pm 1$ $\mathrm{mm} \mathrm{yr}^{-1}$ (McClusky et al. 2000) (figure 3).

The focal mechanism of earthquakes in eastern Anatolian plateau has a dominating northeastsouthwest trend, with a strong strike slip component. The compressive component increases by approaching to Zagros suture zone. The recent 23 October 2011 earthquake in Van was not an exception from a series of compressive events assigned to the Persia plateau. Based on field investigation in Van region, this earthquake belongs to an exposed active reverse fault with $28 \mathrm{~km}$ length (figure 2, zoomed panel), known as the Van fault (Emre et al. 2011).

\section{Applying M8 algorithm}

The main objective of this paper is to demonstrate predictability of major earthquakes on the territory of the Iranian-Turkish plateau, exemplified by a case-study of the 23 November 2011 Van earthquake and the M8 algorithm. It should be noted that it is of crucial importance to determine the application areas before running any prediction algorithm in such a way that the initial conditions are satisfied. Specifically, the seismicity rate in a Circle of Investigation (CI), and distribution of the CI centers in the area under study has a considerable impact on the results of the M8 algorithm application. If we determine CI centers uniformly, without any guidance from tectonics, seismic activity, pattern recognition, etc., our calculations would be exhaustive, though not much informative in many cases and may be even misleading in some cases, e.g., where the actual size of earthquake-prone locus inside a CI is much smaller than its diameter. Hence, different approaches were applied to design an appropriate distribution of CI centers.

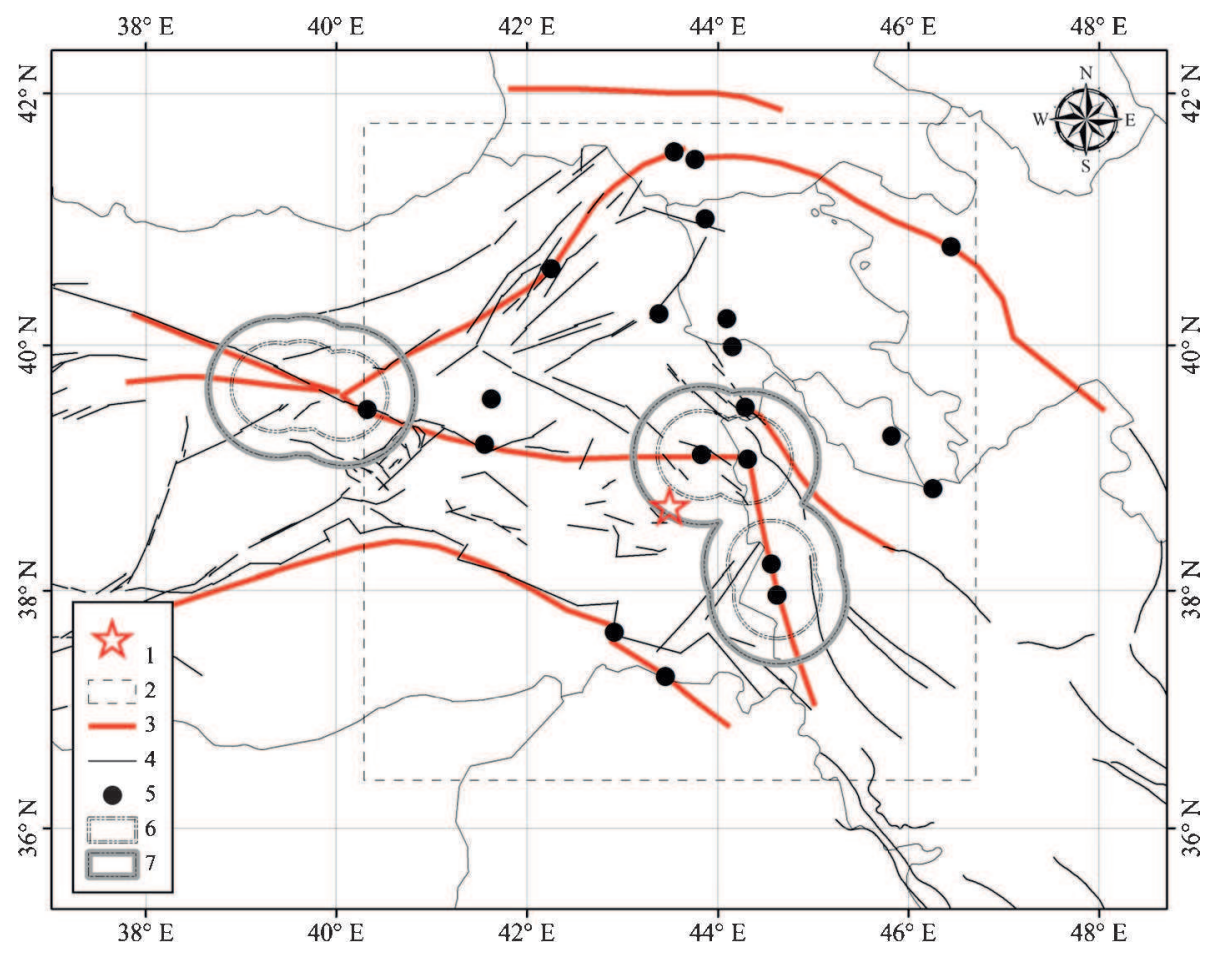

Figure 4. The D-intersections of morphostructural lineaments which have been selected as CIs centers, prone to earthquake of magnitude 6.5+ and 7.0+. (1) Epicenter of the 23 November 2011 Van earthquake; (2) area under study; (3) I-rank lineaments (after Gelfand et al. 1974a); (4) active faults; (5) D-intersections of the lineaments (CIs centers) recognized as prone to earthquake of magnitude $6.5+$ and $7+$ (Gelfand et al. 1974b); (6-7) the 40 and $62.5 \mathrm{~km}$ outline of the D-intersections prone to earthquake of magnitude 6.5+ and 7.0+ (Kossobokov and Rotwain 1977), respectively. 
The first approach makes use of pattern recognition of intersections of morphostructural lineaments with the potential of generating earthquakes of magnitude $6.5+$ and $7+$ (figure 4). These intersections were introduced by Gelfand et al. $(1974 \mathrm{a}, \mathrm{b})$ as dangerous, D-intersections, prone to magnitude

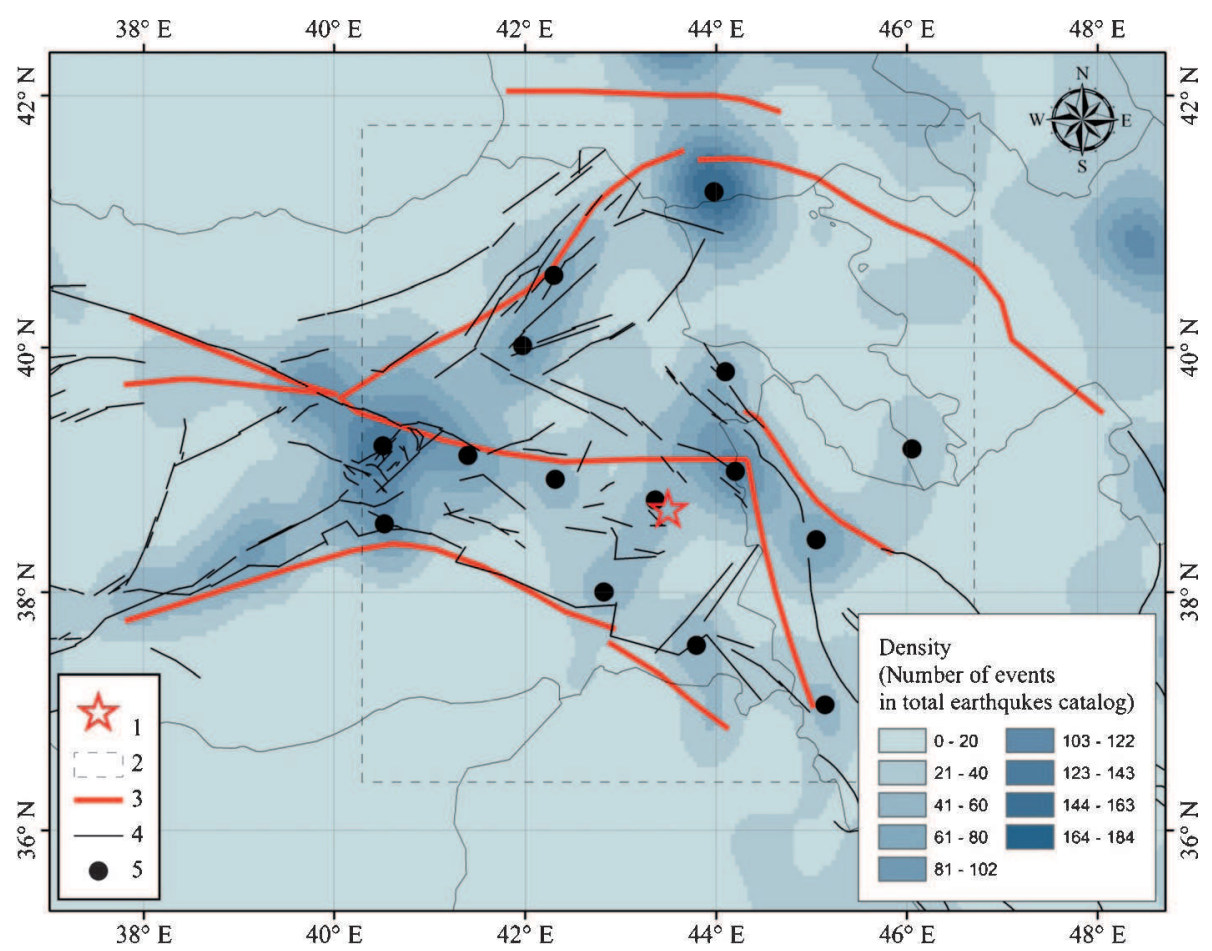

Figure 5. The empirical density of earthquake epicenter distribution. Earthquake density is the number of earthquakes in total duration of a study area catalog. (1) Epicenter of the 23 November 2011 Van earthquake; (2) area under study; (3) I-rank lineaments (after Gelfand et al. 1974a); (4) active faults; (5) centers of the circles of investigation associated with the seismic density distribution patterns.

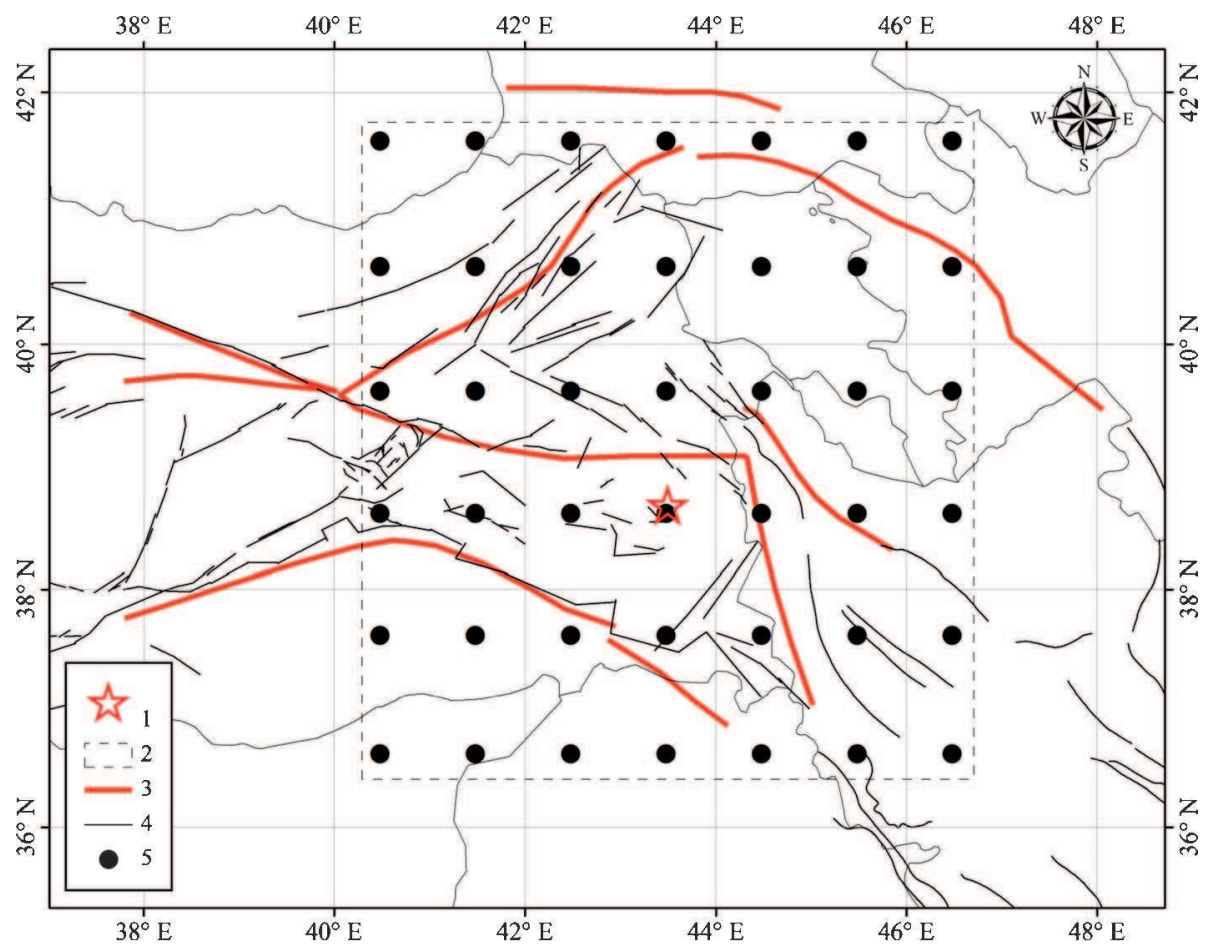

Figure 6. Regular grid of the centers of the CIs for the study area. (1) Epicenter of the 23 November 2011 Van earthquake; (2) area under study; (3) I-rank lineaments (after Gelfand et al. 1974a); (4) active faults; (5) centers of the circles of investigation. 
$6.5+$ earthquakes. Further investigations have shown that some of these intersections have the potential to produce larger earthquakes with magnitudes $7+$ (Kossobokov and Rotwain 1977). In the mentioned studies, the pattern recognition determination of $\mathrm{D}(6.5+)$ - and $\mathrm{D}(7.0+)$-intersections is based on their geomorphologic description and geographic parameters measured in circular areas of the radii comparable to linear dimensions of $\mathrm{M} 6.5+$ and M7.0+ earthquakes (i.e., 25-40 and 40-62.5 km, respectively).

In the second approach, centers of CIs are distributed on local extremes of the seismic density distribution. The map of the associated frequency of earthquakes (figure 5) has been prepared by means of the Kernel method (Silverman 1986). In our case, the Kernel method counts the number of earthquakes in a circular area with a prefixed search radius centered on a pixel and assigns the obtained number to that pixel. In accordance with pattern recognition results (Kossobokov and Rotwain 1977), the search radius in the present study is selected to be $62.5 \mathrm{~km}$.

In the third approach, a regular grid of $1^{\circ} \times 1^{\circ}$ was selected as centers of CIs, regardless of the seismicity distribution and morphostructures (figure 6).

\section{Data}

Catalogs of earthquakes remain the most objective record of seismic activity; that is why most of the studies on seismic precursory phenomena and earthquake prediction, are based on the analysis of earthquake catalogs (Peresan et al. 2005). The earthquake catalog of eastern Anatolian and western Persia plateau regions at latitudes of $33^{\circ}-$ $44^{\circ} \mathrm{N}$ and longitudes of $36^{\circ}-49.5^{\circ} \mathrm{E}$, was selected from the USGS/NEIC Global Hypocenters' Data Base System, GHDB. Following numerical recipes by Shebalin (1992), special searches for duplicates and possible errors were performed. The analysis of the frequency-magnitude graph for considering the consistency of the catalog was accomplished by inspection of the cumulative distribution of earthquake frequency vs. years (figure 7) and the Gutenberg-Richter graph (figure 8). The number of earthquakes vs. years helps recognizing the stability of earthquake occurrence in the area under study. In the 1960's, the quality and completeness of the global catalogs were improved with an installation of the Worldwide Seismic Network. Since 1963, all the earthquakes of magnitude 5 or greater are located and in many areas catalogs are complete to magnitude 4 . As evident from figure 7 , a step in the number of earthquakes appear around 1965, confirming that the GHDB catalog in the study territory is grossly incomplete at magnitude 4.5 before 1965 and reaches reasonable completeness at this level in about one decade. Following this observation, we decided to use the data from 1975 for an application of the modified version of M8 algorithm, although according to the Gutenberg-Richter plots (figure 8), the level of completeness is about magnitude 4.6 in this period of time. (Here we do not investigate the nature of a

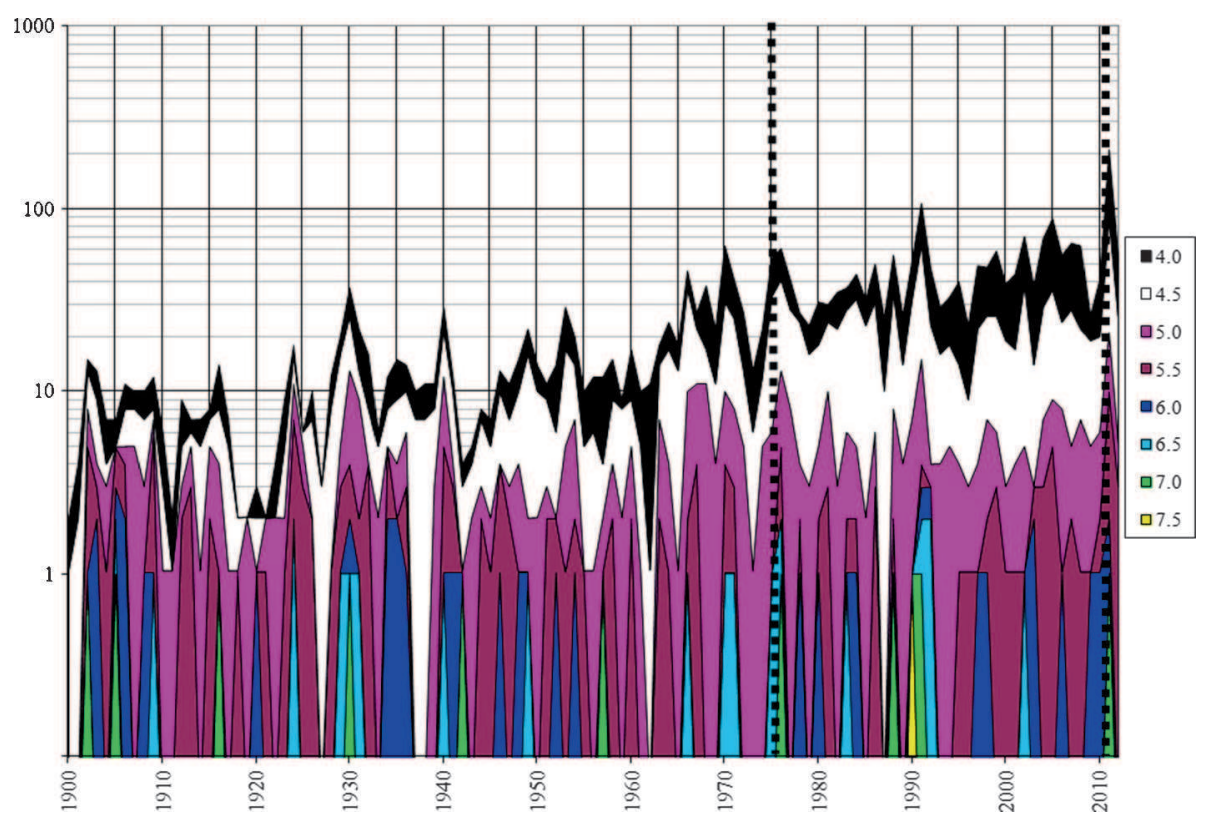

Figure 7. The annual number of earthquakes in the GHDB system in the area of investigation, 1900-2012. Each bound corresponds to a half-magnitude range. These bounds are stacked from higher ranges. Vertical red lines indicate the interval used for the Gutenberg-Richter plot. 


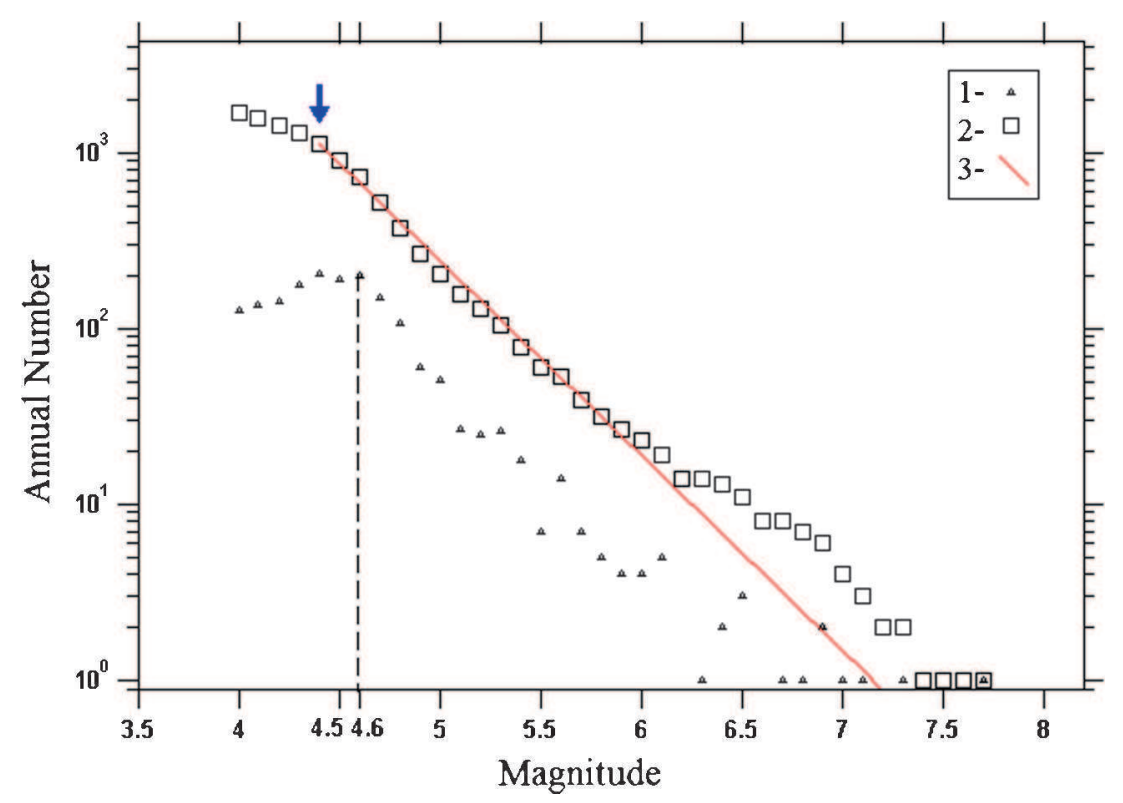

Figure 8. The Gutenberg-Richter plots for the area under study, 1975-June 2011. (1) Annual number of earthquake in a certain magnitude bin; (2) cumulative number of earthquakes summed from higher magnitude ranges; (3) maximum likelihood solution of $\log (N)=a-b M(b=1.11, a=6.36)$. Possible choices of the magnitude of completeness are indicated with a vertical line and an arrow.

remarkable bulge of the plots at above magnitude 6.0 which may signify the overcritical state of earthquake activity on the territory considered in the period associated with seismic extremes.)

\section{Results}

The modified version of M8 algorithm targeting earthquakes from $\mathrm{M} 7.0+$ magnitude range was applied to the entire study area following the three approaches described above. In each case, the 23 October 2011, M7.3 earthquake was used to control, retrospectively, the efficiency of the modified version of M8 algorithm. To adjust an application of M8 algorithm to the local level of the catalog completeness, we have modified the two constants that determine lower magnitude cut-offs (see Appendix A) from $\tilde{N}=20$ and $\tilde{N}=10$ seismic events per year to $\tilde{N}=10$ and $\tilde{N}=5$, respectively. Note that the order of the M8 algorithm parameters does not change the results of TIP diagnosis, therefore, the modification differs by a single one parameter of the original algorithm, i.e., $\tilde{N}=20$ changed for $\tilde{N}=5$.

\subsection{First approach}

Application of the modified M8 algorithm in CIs centered at D-intersections with potential magnitude $7+$ shows that a TIP has been diagnosed from $01 / 07 / 2008$ to $02 / 07 / 2013$ in a single one CI shown in figure 9. The 2011 Van earthquake occurred in this area of alarm and also in the $62.5 \mathrm{~km}$ outline of the D-intersections prone to earthquake of magnitude $7.0+$ (Kossobokov and Rotwain 1977). The graphs of the functions of the M8 algorithm in the period from 1985 to 2011 are shown in figure 10 . All the seven functions involved in the diagnosis of TIP did rise to their anomalous values by mid2008. Accordingly, the 2011 Van earthquake has been predictable using the first approach with an accuracy of 3-4 years and about $200 \mathrm{~km}$.

As illustrated in figure 11, the results of the M8 algorithm application targeting M6.5+ earthquake are formally confirmed by the 2011 Van earthquake, although its epicenter is located away from the triple intersection of CIs in TIPs. As evident from figure 11 , the CIs centered at $\mathrm{D}(6.5+)$ intersections nearest to the M7.3 epicenter did not show a TIP. Both remarks may reflect the accuracy of the M8 predictions and selectivity of this approach in relation to magnitude range: the actual magnitude of M7.3 fits better the range of M7.0+ than that of M6.5+.

\subsection{Second approach}

The same modified version of the M8 algorithm was applied to seismic activity in CIs centered on top of the peaks of earthquake occurrence density. In application targeting M7.0+ earthquakes 8 out of 15 CIs were in state of TIP (figure 12). It is notable that the 2011 Van earthquake epicenter falls into the 8-fold intersection of all the alerted CIs. Thus, following the second approach, the Van earthquake 


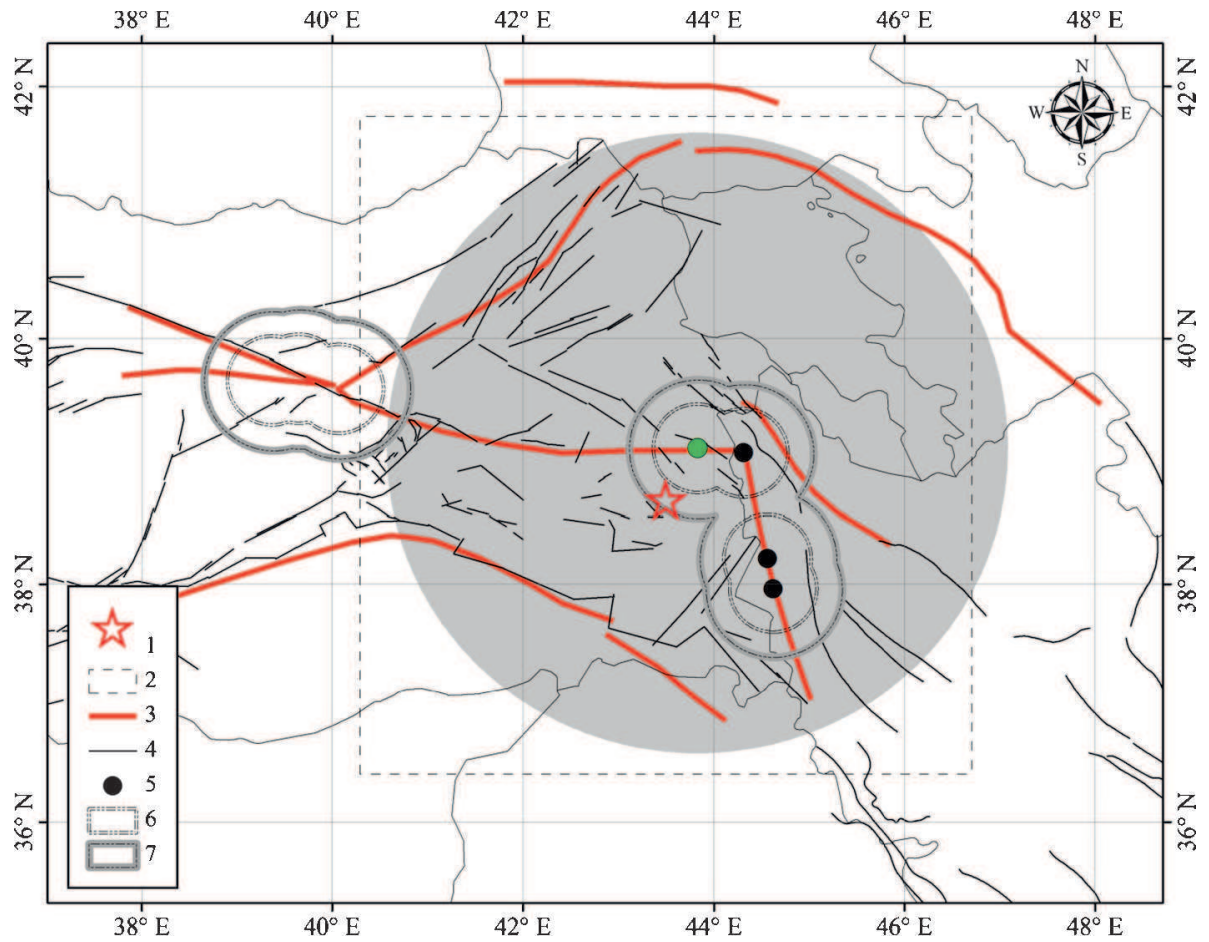

Figure 9. The results of the M8 algorithm application targeting M7.0+ earthquake with $281 \mathrm{~km}$ radius of investigation, as of July 2011: morphostructural intersections. (1) Epicenter of the 23 November 2011 Van earthquake; (2) area under study; (3) I-rank lineaments (after Gelfand et al. 1974a); (4) active faults; (5) D-intersections of the lineaments which are used as CIs centers (after Gelfand et al. 1974b); (6-7) the 40 and $62.5 \mathrm{~km}$ outline of the D-intersections recognized as prone to earthquake of magnitude 6.5+ and 7+, respectively (Kossobokov and Rotwain 1977). Area of TIP diagnosed for the second half-year of 2011 is shaded gray. The center of CI with a TIP marked green.

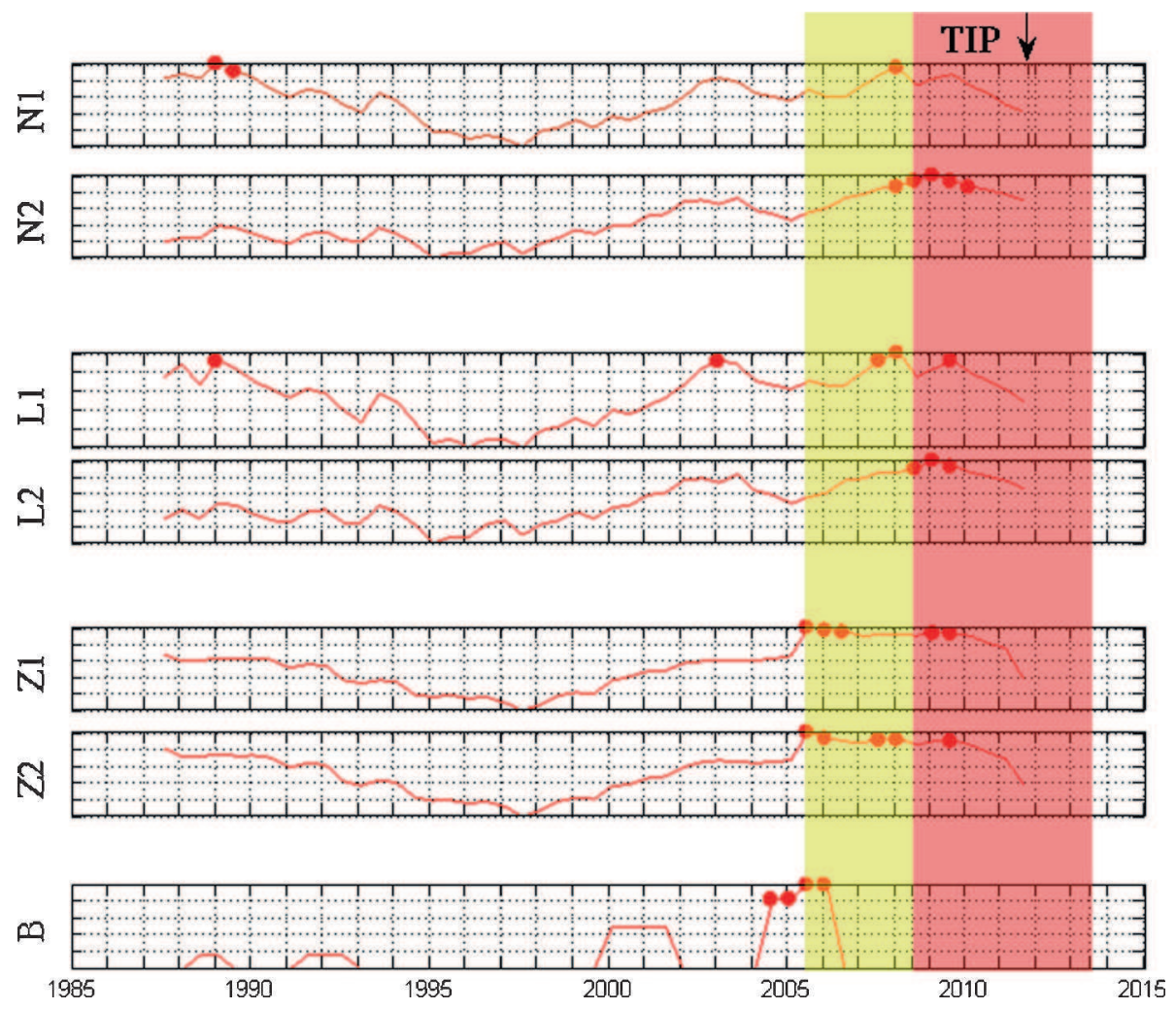

Figure 10. Measures of the M8 algorithm targeting M7.0+ in a CI with a TIP. Functions are normalized to an arbitrary unit ranging from minimal value of 0 to maximal 1 . The anomalous values are marked with red dots. 


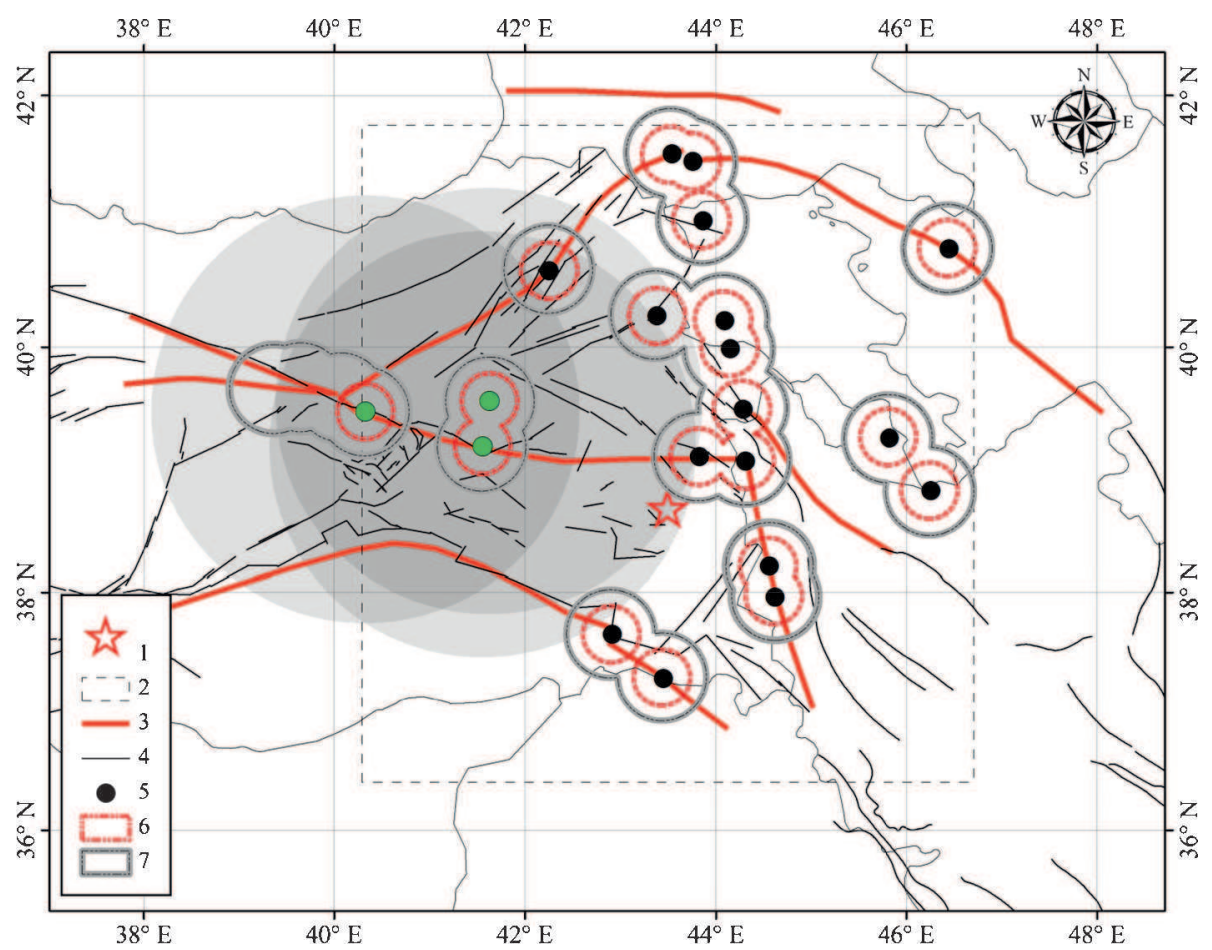

Figure 11. The results of the M8 algorithm application targeting M6.5+ earthquake with $192 \mathrm{~km}$ radius of investigation, as of July 2011: morphostructural intersections. (1) Epicenter of the 23 November 2011 Van earthquake; (2) area under study; (3) I-rank lineaments (after Gelfand et al. 1974a); (4) active faults; (5) D-intersections of the lineaments (after Gelfand et al. $1974 \mathrm{~b})$; (6-7) the 25 and $40 \mathrm{~km}$ outlines of the D-intersections recognized as prone to earthquake of magnitude $6+$ and $6.5+$, respectively. The centers of CIs with TIPs diagnosed for the second half-year of 2011 marked green; the area of TIPs shaded gray.

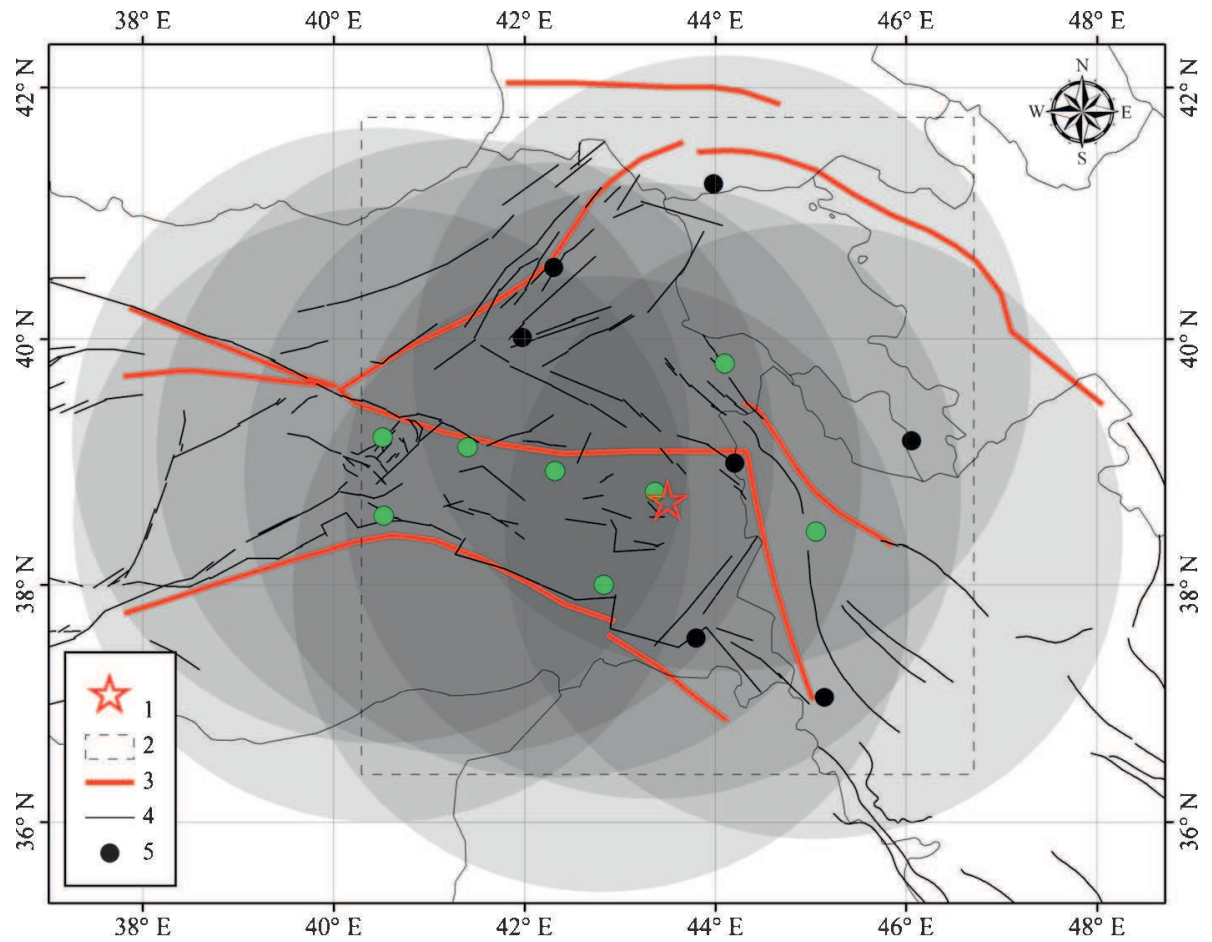

Figure 12. The results of the M8 algorithm application targeting M7+ earthquake with $281 \mathrm{~km}$ radius of investigation, as of July 2011: seismic density traces. (1) Epicenter of the 23 November 2011 Van earthquake; (2) area under study; (3) Irank lineaments (after Gelfand et al. 1974a); (4) active faults; (5) centers of the circles of investigation associated with the seismic density distribution patterns. The centers of CIs with TIPs diagnosed for the second half-year of 2011 are marked green; the area of TIPs shaded gray. The darkest gray area is the intersection of CIs in TIPs. 


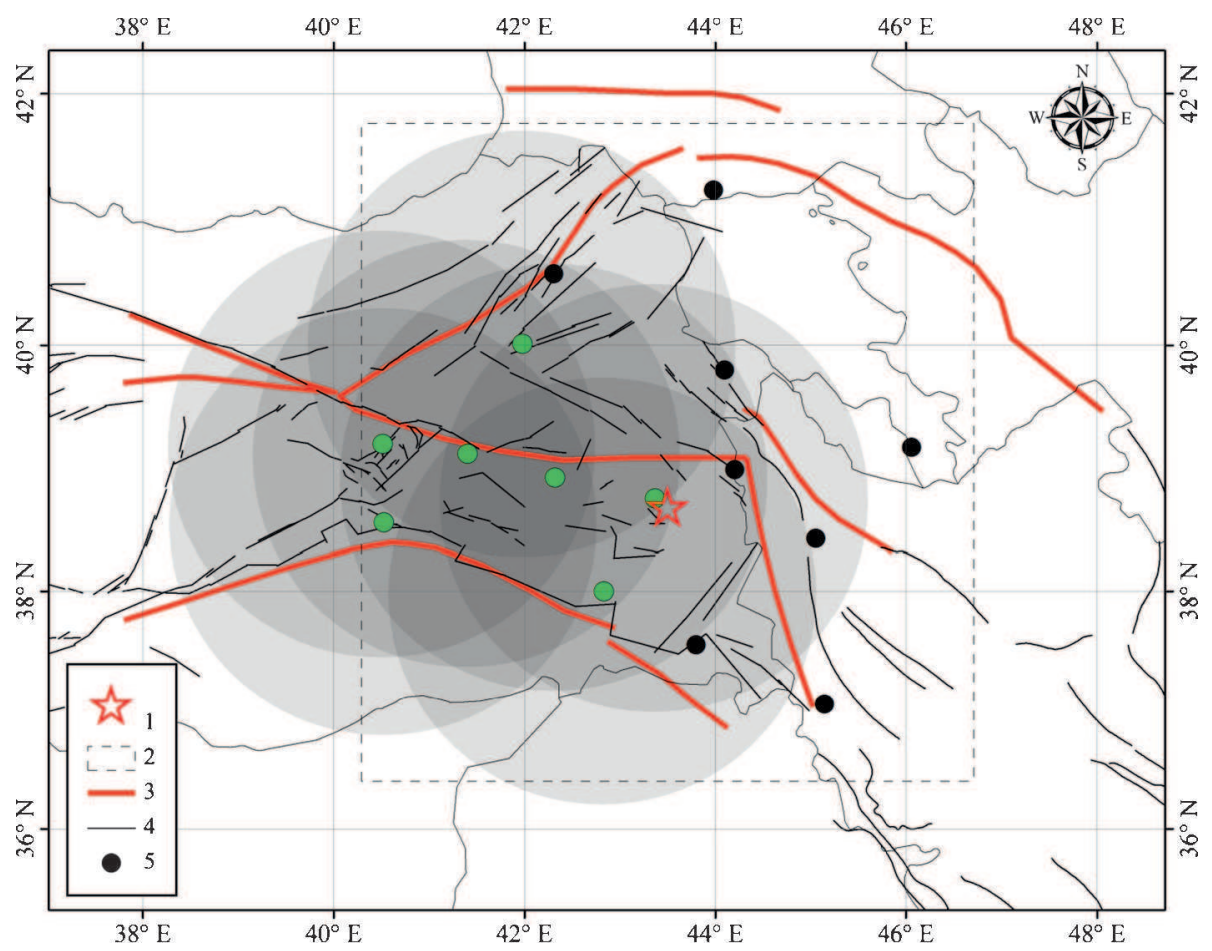

Figure 13. The results of the M8 algorithm application targeting M6.5+ earthquake with $192 \mathrm{~km}$ radius of investigation, as of July 2011: seismic density traces. (1) Epicenter of the 23 November 2011 Van earthquake; (2) area under study; (3) I-rank lineaments (after Gelfand et al. 1974a); (4) active faults; (5) centers of the circles of investigation associated with the seismic density distribution patterns. The center of CIs with TIPs diagnosed for the second half-year of 2011 are marked green; the area of TIPs shaded gray.

could have been predicted using the modified M8 algorithm with the intermediate-term accuracy in time and about $300 \mathrm{~km}$ of this intersection.

A TIP targeting magnitude $6.5+$ is diagnosed in the CI centered at the peak of the seismic density map nearest to and almost at the 2011 Van earthquake epicenter. However, similar to the results of the first approach, the epicenter falls off the 7-fold intersection of the 7 CIs in state of magnitude $6.5+$ alarm (figure 13).

\subsection{Third approach}

The modified M8 algorithm was also applied to a set of CIs centered at the grid points of a regular mesh that covers the territory under study. For 8 out of $42 \mathrm{CIs}$, the number of earthquakes reported in GHDB is insufficient to run even the modified version of the M8 algorithm (figure 14). The diagnosis of TIPs targeting M7.0+ in the remaining 34 CIs is positive for the 11 CIs, which cover almost the entire territory under study. By comparing the results obtained in the first two approaches, we have to conclude that running the M8 algorithm on a regular grid that does not account for tectonics either in terms of specific earthquakeprone morphostructures or empirical earthquake locations could lead to erroneous judgment about the dynamic changes of seismic hazard and associated risks. Same as in the first two approaches, the results of the modified M8 algorithm application targeting magnitude $6.5+$ earthquakes (not shown here) favour a trivial conclusion that predicting a magnitude M7.3 event is better when targeting the range of M7.0+ than that of M6.5+.

\subsection{Stability of the results}

The results of the modified M8 algorithm application as of the 1st of July 2011, described above are obtained with the prefixed starting point of analysis $\mathrm{T}_{\mathrm{o}}=1975$, the beginning $\mathrm{T}_{\mathrm{b}}=1987$, and the ending $\mathrm{T}_{\mathrm{e}}=2011$ of data used for diagnosis of TIP. In this way the periods of 12 and 24 years between $T_{o}$ and $T_{b}$ and between $T_{b}$ and $T_{e}$ are enough to obtain reliable estimates of the M8 functions involved in the TIP diagnosis and their limits of anomalously large values, as approved in course of the M8 algorithm real-time applications worldwide over 25 years (Kossobokov 2014). However, this condition is satisfied just before the 2011 Van earthquake. Following the practice of the first retrospective applications of the M8 algorithm (KeilisBorok and Kossobokov 1990), we have checked both a possibility of error in selecting $\mathrm{T}_{\circ}$ as well as a stability of the modified M8 algorithm applications by simulation of 'seismic history' with $\mathrm{T}_{\mathrm{e}}$ changing from 1997 to 2011, $\mathrm{T}_{\mathrm{o}}=1975$, and 


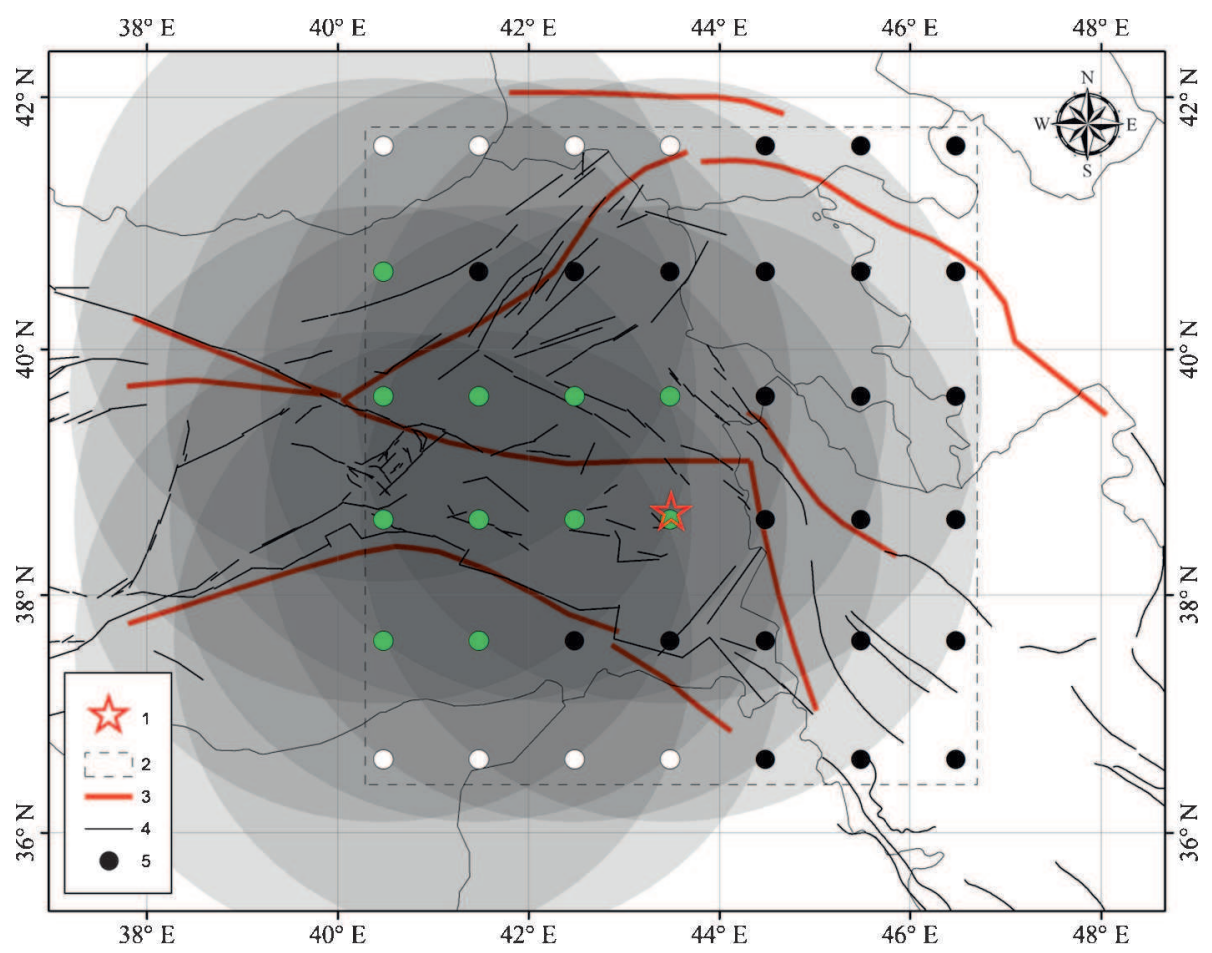

Figure 14. The results of the M8 algorithm application targeting M7.0+ earthquake with $281 \mathrm{~km}$ radius of investigation, as of July 2011: uniform grid. Multiple intersection of CI's with TIP's. The centers of CIs with TIP's are marked green. The number of earthquakes in CI's centered at white points is insufficient for running the modified version of the M8 algorithm.

$\mathrm{T}_{\mathrm{b}}=1987$. The results of these experiments confirm reliability of the TIP diagnostics and its gradual improvement, which appears to stabilize after 2007. Obviously, such a short background of retrospective monitoring in a relatively small region does not allow assessing reliable estimates of statistical significance of the M8 application. However, the 2011 Van earthquake is predictable in all the three approaches, and applications guided by location of D-intersections, and density distribution peaks appear more adequate than that on a regular grid.

\section{Conclusion}

The algorithm used in this study is based on the simultaneous quantitative analysis of a set of precursory seismicity patterns (Keilis-Borok and Kossobokov 1990). These integral seismic symptoms of general activation of seismic static may be interpreted as response of the lithosphere to the tectonic stress. Direct analogies of such a response exist in some other complex non-linear systems including but not limited to solar flares, starquakes, magnetic disturbances, outcomes of elections, starts and ends of economic recessions, episodes of a sharp increase in the unemployment rate, and surges of homicides in a mega-city, etc. (Keilis-Borok 1996; Keilis-Borok et al. 2001; Kossobokov and Soloviev
2008). The on-going global test of M8 has already demonstrated predictability of the world's strongest earthquakes (Kossobokov et al. 1999; Kossobokov and Shebalin 2003; Kossobokov 2011, 2013, 2014). However, there are many challenging questions related to extension of reliable earthquake predictions to lower, yet, hazardous magnitude ranges, as well as to reduction of their temporal and spatial uncertainty.

Present study has demonstrated that the modified version of M8 algorithm is able to respond efficiently to the questions of earthquake forecasting in eastern Anatolia. The alarm area could have been diagnosed in advance of the 23 October 2011, M7.3 Van earthquake. Apparently, the results of retrospective analysis suggest a possibility to increase the accuracy of locating the incipient event by narrowing down the spatial extent of prediction to strong earthquake-prone sites or to the intersection between the alerted areas, which is obviously smaller than each of them. Our test of the three different approaches to application of the M8 algorithm shows that location of centers of CIs plays a vital role emphasized from the very first studies (Kossobokov 1986; Keilis-Borok and Kossobokov 1987). According to our test results, distribution of CIs based on a natural approach accounting for tectonics of the region (i.e., D-intersections and extremes of earthquake spatial density) provides 
more significant and efficient predictions than the one based on a regular grid.

Finally, the present study encourages using the M8 algorithm, which can be applied with little modifications, as a reliable tool to monitor the times of increased probability of earthquake occurrence all over the Iranian-Turkish plateau as well as in other seismic regions worldwide (Keilis-Borok and Kossobokov 1990). We consider the presented case-study targeting predictability of the 2011 Van earthquake as an essential part of learning before its widespread application all over the Iranian plateau for a retrospective check of the modified version of M8 algorithm. In fact, such an application expanded to the entire Iranian Plateau was completed in advance to the two recent earthquakes from M7.5+ range on both sides of the Iran-Pakistan boundary. The results of application in Iranian Plateau along with the evidence of timely real-time prediction of the 16 April 2013, M7.7 Saravan and the 24 September 2013, M7.7 Awaran earthquakes (Mojarab et al. 2014) confirm reliability of the modification of M8 algorithm presented here and its potential in a real-time monitoring of TIPs in Iran and surroundings.

\section{Acknowledgements}

The authors appreciate constructive comments and suggestions of an anonymous reviewer. VK acknowledges the support from the Russian Foundation for Basic Research (grants RFBR Nos. 13-05-91167 and 14-05-92691).

\section{Appendix (M8 algorithm)}

The M8 algorithm is one of the intermediateterm, middle-range earthquake prediction methods. It was designed by retrospective analysis of the dynamics in seismicity preceding the great, magnitude 8.0 or larger earthquakes worldwide (hence its name). Its archetype (Keilis-Borok and Kossobokov 1984) and the original version (Kossobokov 1986; Keilis-Borok and Kossobokov 1987; Kossobokov et al. 1997) were tested retrospectively in the vicinities of the 132 epicenters of earthquakes of magnitude 8.0 or greater recorded between 1857 and 1983. An experiment aimed to test in a real-time prediction mode, the performance of an intermediate-term, middle-range earthquake prediction algorithm M8 at a global scale started in 1992 (Healy et al. 1992). This global test intended to predict the largest earthquakes worldwide has been carried on routinely in real-time for more than 20 years (Kossobokov et al. 1999, 2002; Kossobokov 2013, 2014). The results of the global test prove predictability of earthquakes in the M8.0+ and M7.5+ ranges.

A brief description of the M8 algorithm is as follows:

M8 algorithm is aimed to predict the earthquakes from magnitude range $M M_{0}+=\left[M_{0}, M_{0}+\right.$ $\Delta m]$ where $M_{0}$ is a constant $\Delta m<1$. If the data are adequately complete, a number of target intervals $M_{0} \leq M<\left(M_{0}+\Delta m\right)$, denoted hereinafter as $M M_{0}+$, could be distinguished for different values of $M_{0}$ with an increment of 0.5. In some cases, the actual distribution of earthquake size suggests a natural cut-off magnitude that determines characteristic earthquakes at different levels of seismic hierarchy.

Overlapping circles of investigation, CIs, of the fixed size, proportional to a source of a target earthquake, scan the territory of the seismic region under study. The diameter $D\left(M_{0}\right)=\exp \left(M_{0}-56\right)+1$ in degrees of the Earth's meridian is used for application, i.e., about 5-10 larger than a source of a target magnitude $M M_{0}+$ event.

Within each CI, the sequence of main shocks is considered with aftershocks removed (Gardner and Knopoff 1974; Keilis-Borok et al. 1980). Each main shock is described with a vector $\left\{t_{i}, m_{i}, h_{i}, b_{i}(e)\right\}$, $i=1,2, \ldots$ where $i$ is the main shock number, $t_{i}$ is its origin time, $t_{i} \leq t_{i+1} ; m_{i}$ is its magnitude, $h_{i}$ is its focal depth, and $b_{i}(e)$ is the number of aftershocks with magnitude equal or above prefixed threshold $M_{\text {aft }}$ that happen during the first $e$ days. Sequences in different CIs are normalized to about the same pre-fixed average annual number of earthquakes $\tilde{N}$ by selecting the lower magnitude cut-off $\underline{M}=M_{\min }(\tilde{N})$.

Features of the seismic sequence in time are quantified by computing several running averages in the trailing time window $(t-s, t)$ and magnitude range $M_{0}>M_{i} \geq m$. These counts include:

(i) the number of earthquakes $N(t)$ of magnitude $m$ or greater in time window $(t-s, t)$;

(ii) the deviation of $N(t)$ from longer-term trend, $L(t)$

(iii) linear concentration $Z(t)$ estimated as the ratio of the average source diameter to the average distance between sources; and

(iv) the maximum number of aftershocks $B(t)$.

Specifically, function $N(t)=N(t \mid m, s)$ is the number of earthquakes with $M \geq m$ in time interval from $(t-s)$ to $t$ and represents the rate of seismic activity. Function $L(t)=L\left(t m, s, t_{0}\right)=$ $N(t \mid m, s)-N\left(t-s \mid m, t-s-t_{0}\right) \times s /\left(t-s-t_{0}\right)$ represents deviation of seismic activity from a longerterm trend over the period from $t_{0}$ to $t$. Function $Z(t)=\mathrm{Z}\left(t \mid m, M_{0}-g, s, \alpha, \beta\right)$ represents the linear concentration of earthquake sources, i.e., the 
average source size $(n)^{-1} \times \Sigma 10^{\beta\left(M_{i}-\alpha\right)}$ of earthquakes in time interval from $(t-s)$ to $t$ and magnitude $\left(m \leq M_{i}<M_{0}-g\right)$, divided by the average distance between them $\sim(n)^{-1 / 3}$. (Note that in general $\Sigma 10^{\beta\left(M_{i}-\alpha\right)}$ may estimate different properties of an earthquake depending on the choice of $\beta$, e.g., $\beta \approx 0.5$ for linear dimension, $\beta \approx$ 1.0 for area, and $\beta \approx 1.5$ for volume or energy release.) $B(t)$ characterizes clustering by accounting the maximum of the number of aftershocks $b_{i}(e)$ for earthquakes with $M_{0}-p \leq M_{i}<M_{0}-q$ in time interval from $\left(t-s^{\prime}\right)$ to $t$.

Each of the functions $N, L, Z$ is calculated twice, with a different magnitude cut-off $\underline{M}=M_{\min }(\tilde{N})$, for $\tilde{N}=20$ and 10 , respectively. As a result, the earthquake sequence is represented by a robust averaged description defined by seven functions: $N, L, Z$ (twice each), and $B$. 'Very large' values are identified for each function by using the condition that they are higher than $Q$ percent of the encountered values. A TIP is declared for 5 years, when at least six out of seven functions, including $B$, become 'very large' within a narrow time window $(t-u, t)$. To stabilize the prediction, this criterion is required for two consecutive moments, $t$ and $t+0.5$ years.

The following values of the parameters of $N(t)$, $L(t)$ and $Z(t)$ functions are fixed a priori in the original version of algorithm M8 (Keilis-Borok and Kossobokov 1987): $D\left(M_{0}\right)=\left\{\exp \left(M_{0}-5.6\right)+1\right\}^{0}$ in degrees of the Earth meridian, which is 384,560 , 854 , and $1333 \mathrm{~km}$ for $M_{0}=6.5,7.0,7.5$, and 8, respectively; $s=6$ years, $s^{\prime}=1$ year, $g=0.5$, $p=2, q=0.2, u=3$ years, and $Q=75 \%$ for $B$ and $90 \%$ for the other six functions. Note that such a dimension of the areas of investigation are set proportional to the linear dimensions of the target earthquake sources and are well within the limits (about 3-4 times smaller) of their preparation zone with an estimated radius of $R=10^{0.43 \mathrm{M}} \mathrm{km}$ (Dobrovolsky et al. 1979). This scaling is independently confirmed by Bowman et al. (1998), who claimed that the size of the critical region of accelerated energy release scales with the magnitude of the impending event according to $\log R \sim 0.44 \mathrm{M}$. Clearly, the magnitude scale, which is used in application, should reflect spatial extent of an earthquake source. For many catalogs, this magnitude could be the maximum reported one, e.g., in this paper the maximum magnitude is selected from the four values provided by the National Earthquake Information Center/US Geological Survey Global Hypocenters' Data Base System, i.e., average mb, average $M_{S}$, and the two authoritative magnitudes MA1 and MA2. The performance of the M8 algorithm in the on-going Global Test started in 1992 (Healy et al. 1992) is summed up in table 3.

\section{Glossary}

The circles of investigation, CIs: The M8 algorithm examines seismicity in circular regions. In early testing of the algorithm on magnitude $8+$ earthquakes, the best results were obtained using a radius of six degrees of the Earth meridian, i.e., $667 \mathrm{~km}$. Instrumental observations had established an empirical multiplicative scaling law between magnitude $\mathrm{M}$ and source dimensions, so that Dobrovolsky et al. (1979) estimate the radius of the preparation zone as $100.43 \mathrm{M} \mathrm{km}$, i.e., about $\exp (\mathrm{M})$. After some testing and accounting for an error in location of epicenter, the developers of the M8 algorithm set the relationship between the radius of the $\mathrm{CI}$ and the magnitude of the predicted earthquake, $\mathrm{M}_{0}$, as: $\mathrm{R}\left(\mathrm{M}_{0}\right)=55.5$ $\left(\exp \left(\mathrm{M}_{0}-5.6\right)+1\right) \mathrm{km}$; which gives, $667 \mathrm{~km}$ for magnitude $8.0,427 \mathrm{~km}$ for $7.5,281 \mathrm{~km}$ for 7.0 and $192 \mathrm{~km}$ for 6.5 , since CIs are areas of investigation in which M8 algorithm will run.

TIPs (time of increased probability): A time of increased probability is declared for the CI when five of the first six functions and the seventh function have voted sometime in the preceding three years, and when this condition is met in two successive six-month evaluations. Once a TIP is declared, it lasts for five years. As new data is added to the catalog, the thresholds which cause the functions to vote may change, so a TIP may be terminated early or extended for more than five years. Then TIP is a time of increased probability on each CI.

D-intersections: D-intersections are the morphostructural intersections with the potential of generating earthquakes of magnitude $6.5+$ and $7+$. These intersections were introduced by Gelfand et al. (1974a, b) as dangerous (D-intersections) prone to strong earthquakes. According to the morphostructural investigation (Gelfand et al. 1974a, b), areas prone to earthquakes of $6.5+$ and $7+$ magnitude ranges are determined with circles 40 and $62.5 \mathrm{~km}$ radius, about one source size of the target shocks, respectively (Kossobokov and Rotwain 1977). In this study, we have used these D-intersactions as the centers of CIs with $R_{\left(M_{0}\right)}$ for running M8 algorithm.

\section{References}

Allen C R, Edwards W, Hall W J, Knopoff L, Raleigh C B, Savit C H, Toksoz M N and Turner R H 1976 Predicting earthquakes: A scientific and technical evaluation with implications for society; Panel on Earthquake Prediction of the Committee on Seismology, Assembly of Mathematical and Physical Sciences, National Research Council, US National Academy of Sciences, Washington DC. 
Ambraseys N N 1988 Engineering seismology; Earthquake Eng. Struct. Dynam. 17 1-105.

Ambraseys N N 2009 Earthquakes in the Mediterranean and Middle East: A multidisciplinary study of seismicity up to 1900; Cambridge University Press, UK, 968p.

Berberian F, Muir I D, Pankhurst R J and Berberian M 1982 Late Cretaceous and early Miocene Andean-type plutonic activity in northern Makran and central Iran; J. Geol. Soc. London 139 605-614.

Bird P 2003 An updated digital model of plate boundaries; J. Earth Sci. 4(3) 1027.

Bowman D D, Ouillon G, Sammis C G, Sornette A and Sornette D 1998 An observational test of the critical earthquake concept; J. Geophys. Res. 103(24) 359-372.

Dewey J F, Hempton M R, Kidd F W S, Saroglu F and Sengor A M C 1986 Shortening of continental lithosphere: The neotectonics of eastern Anatolia, a young collision zone; In: Collision Tectonics (eds) Coward M P and Ries A C, Geol. Soc. Spec. Publ. $193-36$.

Dobrovolsky I R, Zubkov S I and Myachkin V I 1979 Estimation of the size of earthquake preparation zone; Pure Appl. Geophys. 117 1025-1044.

Emre Ö, Duman T Y, Özalp S and Elmacı H 2011 Site observations and preliminary evaluation of source fault of 23 October 2011 Van earthquake; Active Tectonics Research Group, MTA Publications, Ankara, Turkey (in Turkish).

Gardner J K and Knopoff L 1974 Is the sequence of earthquakes in southern California, with aftershocks removed, Poissonian? Bull. Seismol. Soc. Am. 64(1) 363-367.

Gelfand I M, Guberman Sh A, Zhidkov M P, Kaletzkaya M S, Keilis-Borok V I, Ranzman E Ia and Rotwain I M 1974a Recognition of places where strong earthquakes may occur. II: Four regions in the Asia Minor and Southeastern Europe; In: Computer analysis of digital seismic data (ed.) Keilis-Borok VI, Comput. Seismol. 7 3-40 (in Russian).

Gelfand I M, Guberman Sh A, Zhidkov M P, Keilis-Borok V I, Ranzman E Ia and Rotwain I M 1974b Recognition of places where strong earthquakes may occur. III: The case when the boundaries of disjunctive knots are unknown; In: Computer analysis of digital seismic data (ed.) KeilisBorok VI, Comput. Seismol. 7 41-58 (in Russian).

Gulkan P, Gurpinar A and Celebi M 1978 Engineering Report on the Muradiye-Çaldıran Turkey earthquake 24 November 1976; National Academy of Sciences, 59p.

Healy J H, Kossobokov V G and Dewey J W 1992 Test to evaluate the earthquake prediction algorithm, M8; US Geol. Surv. Open-File Report 92-401, 23p.

Hough S 2009 Predicting the unpredictable: The tumultuous science of earthquake prediction; Princeton University Press, 272p.

Keilis-Borok V I 1996 Intermediate term earthquake prediction; Proc. Natl. Acad. Sci. USA 93 3748-3755.

Keilis-Borok V I and Kossobokov V G 1984 A complex of long term precursors for the strongest earthquakes of the world; Proc. 27th Geological Congress, Nauka, Moscow $6156-66$.

Keilis-Borok V I and Kossobokov V G 1987 Periods of high probability of occurrence of the world's strongest earthquakes; Comput. Seismol. 19 45-53.

Keilis-Borok V I and Kossobokov V G 1990 Premonitory activation of seismic flow: Algorithm M8; Phys. Earth Planet. Inter. 61 73-83.

Keilis-Borok V I, Knopoff L, Rotvain I M and Sidorenko T M 1980 Bursts seismicity as long-term precursors of strong earthquake; J. Geophys. Res. 85 803-811.

Keilis-Borok V I, Ismail-Zadeh A T, Kossobokov V G and Shebalin P 2001 Non-linear dynamics of the lithosphere and intermediate-term earthquake prediction; Tectonophys. 338 247-260.
Kossobokov V G 1986 The test of algorithm M8; In: Algorithms of Long-Term Earthquake Prediction (ed.) Sadovsky MA, CERESIS Lima, Peru, pp. 42-52.

Kossobokov V G 1997 User manual for M8; In: Algorithms for Earthquake Statistics and Prediction (eds) Healy J H, Keilis-Borok V I and Lee W H K, IASPEI Software Library, vol. 6, Seismol. Soc. Am. El Cerrito, CA.

Kossobokov V G 2011 Are mega earthquakes predictable? Izvestiya, Atmos. Oceanic Phys. 46(8) 951-961.

Kossobokov V G 2013 Earthquake prediction: 20 years of global experiment; Nat. Hazards 69 1155-1177, doi: 101007/s11069-012-0198-1.

Kossobokov V 2014 Chapter 18. Times of increased probabilities for occurrence of catastrophic earthquakes: 25 years of hypothesis testing in real time; In: Earthquake hazard, risk, and disasters (eds) Wyss M and Shroder J (London: Elsevier), pp. 477-504.

Kossobokov V G and Rotwain I M 1977 Recognition of places where strong earthquakes may occur. VI. Magnitude $\mathrm{M} \geq 7.0$; In: Pattern recognition and spectral analysis in seismology (ed.) Keilis-Borok VI, Comput. Seismol. 10 3-13 (in Russian).

Kossobokov V G and Shebalin P 2003 Earthquake prediction; In: Nonlinear Dynamics of the Lithosphere and Earthquake Prediction (eds) Keilis-Borok V I and Soloviev A A, Springer, Heidelberg, pp. 141-207.

Kossobokov V G and Soloviev A A 2008 Prediction of extreme events: Fundamentals and prerequisites of verification; Russian J. Earth Sci. 10 ES2005, doi: 102205/ 2007ES000251.

Kossobokov V G, Healy J H and Dewey J W 1997 Testing an earthquake prediction algorithm; Pure Appl. Geophys. 149 219-232.

Kossobokov V G, Romashkova L L, Keilis-Borok V I and Healy J H 1999 Testing earthquake prediction algorithms: Statistically significant real-time prediction of the largest earthquakes in the Circum-Pacific, 1992-1997; Phys. Earth Planet. Inter. 111(3-4) 187-196.

Kossobokov V G, Romashkova L L, Panza G F and Peresan A 2002 Stabilizing intermediate-term middlerange earthquake predictions; J. Seismol. Earthq. Eng. 8 11-19.

McClusky S et al. 2000 Global Positioning System constraints on plate kinematics and dynamics in the eastern Mediterranean and Caucasus; J. Geophys. Res. 105 5695-5719.

McKenzie D P 1972 Active tectonics of the Mediterranean region; Geophys. J. Astron. Soc. 30 109-185.

Mojarab M, Memarian H, Zare M and Kossobokov V 2014 Adjusting the earthquake prediction algorithm M8 for application in Iranian Plateau with special reference to the 16 April 2013, M7.7 Saravan and the 24 September 2013, M7.7 Awaran earthquakes (Manuscript).

Peresan A, Kossobokov V G, Romashkova L and Panza G F 2005 Intermediate-term middle-range earthquake predictions in Italy: A review; Earth-Sci. Rev. 69 97-132.

Reilinger R S, McClusky P, Vernant S, Lawrence S, Ergintav R, Cakmak H, Ozener F, Kadirov I, Guliev R, Stepanyan M, Nadariya G, Hahubia S, Mahmoud K, Sakr A, ArRajehi D, Paradissis A, Al-Aydrus M, Prilepin T, Guseva E, Evren A, Dmitrotsa S V, Filikov F, Gomez R and Al-Ghazzi K G 2006 GPS constraints on continental deformation in the Africa-Arabia-Eurasia continental collision zone and implications for the dynamics of plate interactions; J. Geophys. Res. 111 B05411, doi: 101029/ 2005JB004051.

Sengör A M C 1990 A new model for the late PalaeozoicMesozoic tectonic evolution of Iran and implications for 
Oman; In: Geology and tectonics of the Oman Region, Geol. Soc. London, Spec. Publ. 49 797-831.

Sengör A M C and Kidd W S F 1979 Post-collisional tectonics of the Turkish-Iranian plateau and a comparison with Tibet; Tectonophys. 55 361-376.

Shebalin P N 1992 Automatic duplicate identification in set of earthquake catalogues merged together; Open-File Rep., US Geol. Surv., pp. 92-401 (Appendix II).

Silverman B W 1986 Density Estimation for Statistics and Data Analysis; Chapman and Hall, New York.
Taymaz T, Jackson J A and McKenzie D 1991 Active tectonics of the north and central Aegean Sea; Geophys. J. Int. $106403-490$.

Tchalenko J S and Berberian M 1974 The Salmas (Iran) earthquake of May 6, 1930; Annali di Geofisica 27 $1-2$.

Zare M, Haghshenas E and Bastami M 2011 The Van, Turkey Earthquake of 23 October 2011; A Preliminary Report on the Reconnaissance Visit preformed by IIEES Reconnaissance Team.

MS received 9 July 2014; revised 3 February 2015; accepted 12 February 2015 